\title{
MODULAR STRATEGY
}

\section{Dear Reader,}

It is a well-known fact that engines have become increasingly complex over the past few decades, and it is a process that is still ongoing today. Further reductions in $\mathrm{CO}_{2}$ emissions through downsizing and electrification as well as the introduction of the Euro 6 standard for diesel engines are just some of the current technical challenges. And in spite of all this innovative technology, the main focus is still on costs and product quality.

Whenever I talk to experts about these issues, they soon mention the term "modular strategy" as a key approach. Modules that can be flexibly combined to create space for a wide range of technical implementations - freely scalable, from minimum to maximum, from a basic engine to a high-tech powertrain. Of course, these concepts require huge initial investment, as modularisation usually requires a complete redesign of the powertrain platform, or at least the complex and cost-intensive adaptation of all systems and components. The costsaving potential then becomes apparent over the production period. In addition to greater flexibility, modularity also means high production volumes, in other words low-cost, high-quality mass production of innovative products.

It comes as no surprise, therefore, that it is the big, multi-brand car makers like Volkswagen or General Motors who are pushing ahead with this strategy. The losers are likely to be smaller manufacturers who do not have sufficient capital for a complete implementation of a modular concept or, even if they have a modular strategy, do not have enough purchasing power to benefit from the funda- mental advantages of this concept. Even selective cooperation on individual projects, as is currently being advanced by some car makers for cost reasons, will, in my opinion, be made much more difficult in the future if a modular strategy is consistently implemented - manufacturers would have to deviate too far from their in-house standards in order to be compatible with the products of their cooperation partner.

One solution for smaller market players might be modular strategies that include several manufacturers, as these would result in a corresponding purchasing volume. I recommend considering this option with an open mind and going beyond hierarchical in-company thinking. What is your opinion? Please send your comments to me by email at Richard.Backhaus@ rb-communications.de or use the blog at www.ATZonline.de.

Best regards,

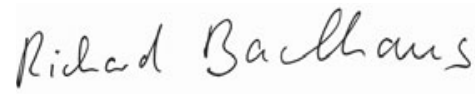

RICHARD BACKHAUS,

Vice-Editor in Chief

Wiesbaden, 12 July 2012



